\title{
Using a Standardized Patient Model for Interprofessional Team Training in Social Work
}

\author{
Laurel Iverson Hitchcock \\ Allison Shorten \\ Peter Bosworth \\ Shawn Galin \\ Tara Edmonds \\ Caroline Harada
}

\begin{abstract}
The purpose of this article is to describe the development of a single-session Interprofessional Team (IPT) Training that incorporates the practice of interprofessional teamwork using a health care case study. We will share how a large-scale training that requires interprofessional teams of students to create a treatment plan of care for a standardized patient developed over time and how this experiential learning activity affects learning outcomes for social work students related to interprofessional awareness and teamwork skills. Additionally, we will explore the use of video technology as a pedagogical approach to presenting standardized patients to students. Student responses from three IPT Training sessions provided the data discussed in this article. While overall results are mixed about students' learning outcomes, trends in the data show this single-session, interprofessional training involving a standardized patient as a promising practice. Lessons learned for social work education are also discussed. The present study advances the field of interprofessional simulation by contributing to our understanding of how a team-based training combined with a standardized patient can be used to increase social work students' professional awareness about interprofessional teamwork.
\end{abstract}

Keywords: Standardized Patient, interprofessional education, technology-mediated

As defined by the World Health Organization (2010), interprofessional education (IPE) occurs when two or more professions learn about, from and with each other to enable effective collaboration and improve health outcomes for individuals and communities. IPE is now considered an essential part of the curricula in US colleges and universities that are educating the next generation of health care professionals, including social work education (Council on Social Work Education [CSWE], 2015; Interprofessional Education Collaborative [IPEC], 2019). While IPEC (2016) offers guidance for key competencies needed by students graduating from health care degree programs, the questions of how and when to incorporate IPE learning activities into curricula is a challenge for educators across all healthcare professions. In this article, we explore the development, implementation, and evaluation of an IPE learning activity at one university that uses a standardized patient

Laurel Iverson Hitchcock, PhD, MPH, LICSW, Associate Professor, Department of Social Work, College of Arts \& Sciences; Allison Shorten PhD, RN, FACM, FAAN, Professor and Department Chair, School of Nursing and Director, Office of Interprofessional Curriculum [OIPC], Center for Interprofessional Education and Simulation [CIPES]; Peter Bosworth, MBA, Program Director, OIPC, CIPES; Shawn Galin, PhD, Associate Professor of Medicine, Department of Medicine, Division of Pulmonary and Critical Care Medicine, and Director, Office of Standardized Patient Education [OSPE], CIPES; Tara Edmonds, PhD, Director of Assessment, OSPE, CIPES; and Caroline Harada, MD, Associate Professor of Medicine, Department of Medicine, Division of Gerontology, Geriatrics, \& Palliative Care and Assistant Dean for Community-Engaged Scholarship, School of Medicine, University of Alabama at Birmingham, Birmingham, AL. 
model with large groups of students from nine professions including social work, nursing, and medicine, and report on how this activity affects social work students' perceptions of interprofessional collaboration.

\section{Benefits and Challenges of IPE}

Innovative interprofessional curriculum is critical for preparing a future healthcare workforce in the US that is capable of serving the increasingly complex needs of patients living in our community. Optimizing patient experiences, improving population health, and bettering the working lives of healthcare providers, while simultaneously reducing costs, known as the quadruple aim of healthcare delivery, necessitates working in highly functional interprofessional teams (Bodenheimer \& Sinsky, 2014). Effective interprofessional communication, role clarity and teamwork are critical for patient safety. Higher team functioning in the context of interprofessional models of care is associated with lower mortality rates and better health outcomes for patients ( $\mathrm{Wu}$ et al., 2018). Interprofessional healthcare teams, working within coordinated models of care, can reduce patient length of stay, improve patient health and health literacy and prevent readmission to hospital (Berwick \& Hackbarth, 2012; Blewett et al., 2010).

Students in healthcare professions must be trained in effective, meaningful participation in interprofessional teamwork in order to provide them with the skills necessary to succeed in our current and future healthcare systems. Purposefully designed, interprofessional, team-based learning experiences, have demonstrated potential to improve student attitudes and skills in working with other professional groups (Kaminetzky et al., 2017; White et al., 2013; Wu et al., 2018). Additionally, high quality interprofessional educational experiences for interprofessional learners include a clear rationale, outcome-based goals, deliberate design, and coordinated assessment and evaluation (Health Professions Accreditors Collaborative, 2019). Educational experiences are capable of breaking down the traditional barriers to build mutual respect, appreciation for shared knowledge and shared experiences, while helping students to appreciate the roles and responsibilities each profession brings to the healthcare team (Homeyer et al., 2018).

Educators tasked with preparing students for the interprofessional healthcare workforce of the future, require resources and willingness to step outside traditional professional silos with the explicit goal of helping students learn from, with, and about other professions in the healthcare team. Logistic challenges can be significant and are often reported as key barriers limiting widespread use of interprofessional education across U.S. college campuses. Barriers to interprofessional education include lack of designated funding for activities, high volume of learners, space and time limitations, and diverse program curricula requirements (Freeth \& Reeves, 2004). Interprofessional education programs should therefore be designed with the intent of overcoming known barriers and promoting enablers to developing skills in effective interprofessional teamwork and communication. In this paper, we share how a large-scale training that requires interprofessional teams of students to create a treatment plan of care for a standardized patient developed over time to address many of these common logistical challenges. 


\section{IPE in Social Work Education}

The social work profession has long articulated the need for interprofessional education, especially for social workers practicing in settings where social work is not the dominant profession such as hospitals and schools. At the annual meeting of the Council on Social Work Education (CSWE) in 1968, Dana, along with colleague Dr. Sheps noted that "the successful outcome of new educational ventures into interprofessionalism will be dependent upon the degree to which professional schools themselves demonstrate the principles of interprofessional behavior in designing and implementing new ways for students to learn together" (Dana \& Sheps, 1968, p. 41). More recently, this call to action has been operationalized by the CSWE's membership in the Interprofessional Education Collaborative (IPEC) in 2016 as well as CSWE's 2018 annual conference being devoted to the theme of interprofessional education. Further, current leaders in social work education have been calling for more emphasis on practical and meaningful educational experiences where social work students are at the same table as students from other professions, learning about other professions' roles as well as effective collaborative processes (Jones \& Phillips, 2016; Rubin et al., 2018)

Among social work curricula, IPE has been a growing area of educational innovation. Recent studies of various IPE activities with social work students have shown positive student learning outcomes associated with attitudes and beliefs toward interprofessional collaboration. For example, Wharton and Burg (2017) found that working with medical and pharmacy students on health-related cases increased social work students' confidence in their role on an interprofessional healthcare team. Others have found that social work students can learn about how poverty affects health outcomes by participating in a teambased poverty simulation with other professions such as nursing and occupational therapy (Hitchcock et al., 2018; Vandsburger et al., 2010). Additionally, the social work profession has demonstrated diversity in IPE by working with disciplines such as K-12 education, business, and social innovation as well as the traditional health care professions (Archibald et al., 2016; Lopez et al., 1998). As more social work educational programs expand their curricular efforts to incorporate interprofessional skills for teamwork, faculty will need to develop evidence-informed practices that promote positive student learning outcomes across a variety of educational activities.

\section{Standardized Patient Model in IPE}

One important modality of interprofessional education involves the use of standardized patients (SPs). SP methodology provides a gold standard for education and assessment of learner performance in a clinical health care setting (Palaganas et al., 2014). SPs are individuals who have been trained to portray a patient in a scripted case scenario and are able to consistently deliver a standardized performance when interacting with different students or groups of students. The use of SP methodology in formative educational activities and high stakes summative assessment has been extensively documented and its ability to bring the human touch to simulation is undeniable (Kaplonyi et al., 2017).

The use of SP methodology in IPE allows students to practice acquired skills and behaviors around patient care while gaining knowledge from the nuances associated with 
human interaction. In IPE, working with an SP while simultaneously interacting with other health professional students can foster insight and understanding into individual roles and tasks within the healthcare team (Wamsley et al., 2012). In addition, education around communication skills is a hallmark of SP methodology. It has been shown that practicing interpersonal communication with SPs results in better communication skill acquisition than practice with peers (Schlegel et al., 2012). While the use of SPs to enhance interprofessional communication and teamwork has been reported, this has commonly been done in small group settings (Bays et al., 2014; Foronda et al., 2016). Small group settings do aid in recreating the healthcare team approach by selectively limiting number and types of participants. However, small group formats do raise certain curricular design challenges when dealing with large numbers of students representing many schools. Designing large group interprofessional activities, particularly those involving considerable student cohorts, often come with logistical and financial challenges. The use of virtual patients or web-based SP encounters can provide a platform to assure learners are provided equal opportunity often at a lower cost to stakeholders (Lempicki \& Holland, 2018; Reis et al., 2015). Here, we will report the use of videotaped patient interviews using a SP that combines patient history acquisition with continuum of care.

\section{Standardized Patients in Social Work Education}

Scholarship about the use of standardized patients or clients in social work education primarily follows two models - a formative SP-based learning experience, and summative encounters (e.g., objective structured clinical exams). The formative learning experience typically involves an actor or theatre student in the role of a client who is based on a case study developed by a faculty member with the goal of improving student skills and competency related to specific course content (Badger \& MacNeil, 2002; Mooradian, 2008). Research on these learning experiences has found that the use of SP Methodology can increase interviewing and assessment skills as well as their knowledge about specific clinical situations such as domestic violence or adolescent sexuality (Forgey et al., 2013; Logie et al., 2015). Other examples of the formative use of a standardized patient model in social work includes virtual patients to increase knowledge about brief assessment skills in medical settings (Hitchcock et al., 2019; Washburn \& Zhou, 2018), and live patients to practice interprofessional communication skills among a team of health care students (Wharton \& Burg, 2017).

This article describes the development, implementation, and evaluation of a singlesession training that incorporates the practice of interprofessional teamwork using a SP health-based case. The authors will meet this aim in two ways. First, we will describe the large-scale training that requires interprofessional teams of students to create a treatment plan of care for a SP which has been developed over time and how this experiential learning activity affects learning outcomes for social work students related to interprofessional awareness and teamwork skills. We will also explore the use of video technology as a pedagogical approach to presenting standardized patients to students, which can provide efficiency in educational delivery and mitigate the need for multiple spaces and extensive human resources when providing valuable IPE content to hundreds of learners from multiple health professional schools. Second, we will share data about student responses 
from three Interprofessional Team Training (IPTT) sessions, providing a combination of quantitative and qualitative data that informs student learning. Lessons learned from IPTT are discussed for IPE generally and for social work education specifically.

\section{Method}

\section{Description of Interprofessional Team (IPT) Training Activity}

The University of Alabama at Birmingham (UAB) IPTT was originally conceived and designed in 2009 as a part of the Health Resources and Services Administration-funded UAB Geriatrics Education Center (UAB GEC) to provide an opportunity for health professions students to experience interprofessional team-based care (Rothrock et al., 2013). In its earliest iterations, large groups of 300-350 students from nine health professions (Social Work, Nursing, Medicine, Pharmacy, Dentistry, Occupational Therapy, Physical Therapy, Optometry and Nutrition) gathered in a lecture hall for a 60minute presentation. After a brief introduction to interprofessional teamwork, a real patient was interviewed sequentially by a professional, typically a faculty member, from each of the nine different health professions, and students were tasked to take notes. Each professional had approximately 5-minutes to ask questions to complete their assessment and were asked to focus their questions on specific aspects of their scope of practice. For example, the social work faculty frequently asked questions of the real patient about family involvement and financial resources.

Students then divided into smaller interprofessional groups for a 75-minute discussion to debrief the interview and develop an interprofessional care plan, facilitated by a proctor who was a faculty or staff member accustomed to working in interprofessional teams. This activity continues to be conducted twice a year in the Fall and Spring Semesters, although it has been modified considerably over the years due to several challenges inherent in the original model. First, using real patients meant that sometimes the interview would take off in unexpected directions, and some patients did not bring up issues that provided content to engage students from each of the health professions participating in the training. Second, the session had to be held on a Friday afternoon because of scheduling constraints, and usually took about three hours, resulting in frequent complaints from students about the timing. Third, while students usually became quite engaged during the interprofessional team small group discussion, they sometimes found the introductory lecture and interview demonstration to be long and tedious. Fourth, the session often lost momentum during the transition from large lecture hall into small group meetings, as simply getting that many students up the stairs or elevators to the small group rooms took about fifteen minutes.

Because of these persistent challenges, the experience was eventually re-designed in two phases. Table 1 shows an overview of how the training changed over time. In the 2017 revision, we moved to using a standardized patient in place of a real patient. The standardized patient approach allowed us to craft a clinical case with features to engage learners from a wide variety of participating professions, and teaching points could be prepared in advance. At this time, the activity name was changed to IPT Training to better illustrate the learning goals. To address remaining challenges, in 2018 we undertook a second revision in which we eliminated the large group session altogether and moved to a 
distributed model. In this model, students reported to small group rooms at the start of the activity. The patient interview was replaced by a 4-minute video of a standardized patient talking about his various health-related problems. Table 1 provides a summary of the different models of this training for the following elements: 1) amount of time allotted for the training; 2) predictability of the standardized patient; 3) physical space requirements; and 4) proctor requirements.

Table 1. Summary of the three IPT Training Models

\begin{tabular}{|c|c|c|c|}
\hline \multirow[b]{2}{*}{ Element } & \multicolumn{3}{|c|}{ Model } \\
\hline & $\begin{array}{l}\text { Real Patient } \\
(2009-2016)\end{array}$ & $\begin{array}{l}\text { Live Standardized Patient } \\
\text { (2017) }\end{array}$ & $\begin{array}{c}\text { Distributed } \\
\text { (2018 to present) }\end{array}$ \\
\hline Time required & $\begin{array}{l}\text { 2.5 hours } \\
\text { - } 15 \text { min lecture } \\
\text { - } 45 \text { min patient interview } \\
\text { - } 15 \text { min room transition } \\
\text { - } 75 \text { min small group } \\
\text { discussion }\end{array}$ & $\begin{array}{l}\text { 2.5 hours } \\
\text { - } 15 \text { min lecture } \\
\text { - } 45 \text { min patient interview } \\
\text { - } 15 \text { min room transition } \\
\text { - } 75 \text { min group discussion }\end{array}$ & $\begin{array}{l}\text { 1.5 hours } \\
\text { - } 4 \text { min video } \\
\text { - } 86 \text { min small group } \\
\text { discussion }\end{array}$ \\
\hline Predictability & Low & Moderate to High & High \\
\hline $\begin{array}{l}\text { Physical space } \\
\text { requirements }\end{array}$ & $\begin{array}{l}\text { Large lecture room, } \\
\text { followed by multiple } \\
\text { small group rooms }\end{array}$ & $\begin{array}{l}\text { Large lecture room, } \\
\text { followed by multiple } \\
\text { small group rooms }\end{array}$ & $\begin{array}{l}\text { Multiple small group } \\
\text { rooms only }\end{array}$ \\
\hline $\begin{array}{l}\text { Faculty proctor } \\
\text { requirements }\end{array}$ & $\begin{array}{l}\text { - } 1 \text { lecturer } \\
\text { - } 1 \text { patient interviewer } \\
\text { from each profession } \\
\text { - } 1 \text { facilitator for each } \\
\text { small group }\end{array}$ & $\begin{array}{l}\text { - } 1 \text { lecturer } \\
\text { - } 1 \text { patient interviewer } \\
\text { from each profession } \\
\text { - } 1 \text { facilitator for each } \\
\text { small group }\end{array}$ & $\begin{array}{l}\text { - } 1 \text { facilitator for each } \\
\text { small group }\end{array}$ \\
\hline
\end{tabular}

An overview of the Distributed Model for the IPT Training can be found in Table 2, from start to finish. The training starts with some preparatory information which is sent to students via email. They are given their group room assignments and are directed to resources to help them craft their "elevator speech". On the day of the event, students arrive directly to their assigned room. The faculty preceptor screens the video, and then students break into pairs to give a 30-second summary outlining their profession's scope of practice. The next part of the training is an interactive group discussion. Students then discuss the case in detail, and work as an interprofessional team to develop their own care plan for the patient. This new model takes about 90 minutes to complete, which considerably improved student satisfaction on a Friday afternoon and eliminated both the long-observed interview component, and the cumbersome transition times seen with the previous model.

Faculty preceptors for the small groups are recruited from a large pool of experienced faculty, many of whom have been with this activity since the beginning. Using a "train-the -trainer" approach to maintain quality and consistency, new faculty volunteers are paired with an experienced preceptor the first time they participate to get a realistic preview before they facilitate a small group on their own. The focus on preceptor training is to provide strategies that will enable preceptors to create opportunities for students to practice effective interprofessional communication and teamwork regardless of the mix of professions within the group. 
Table 2. Elements of Distributed Model of IPT Training Activity

\begin{tabular}{|c|c|}
\hline Duration/Timing & Activity \\
\hline Pre-work & $\begin{array}{l}\text { Learners are emailed resources to help them prepare a } 30 \text { second "elevator } \\
\text { speech" outlining their scope of practice and "myths" about their profession. }\end{array}$ \\
\hline $\begin{array}{l}30 \text { min. prior to } \\
\text { session }\end{array}$ & $\begin{array}{l}\text { Preceptors gather for lunch and briefing. Learning goals, session flow and } \\
\text { expectations are communicated. New preceptors are paired with } \\
\text { experienced faculty. }\end{array}$ \\
\hline $10 \mathrm{~min}$. & Learners watch standardized patient video \\
\hline $15 \mathrm{~min}$. & $\begin{array}{l}\text { Introductions, aims, elevator speeches, review patient information, pre- } \\
\text { activity attitudes/skills evaluation }\end{array}$ \\
\hline $5 \mathrm{~min}$. & Intraprofessional discussion for each group of professional students \\
\hline $5 \mathrm{~min}$. & $\begin{array}{l}\text { Consider what additional information might be needed. Reflect on role } \\
\text { overlaps/differences }\end{array}$ \\
\hline $40 \mathrm{~min}$. & Learners prioritize goals for patient care and develop a care plan \\
\hline 15 min. & $\begin{array}{l}\text { Reflection: role similarities/differences, cross profession interaction, } \\
\text { "takeaways" }\end{array}$ \\
\hline $\begin{array}{l}10 \text { days after } \\
\text { activity }\end{array}$ & Learners sent link to post- activity attitudes/skills evaluation \\
\hline
\end{tabular}

\section{Standardized Patient}

Because the original IPT Training was developed by the Geriatrics Education Center at (de-identified), the SP is an older adult with multiple health care problems. Along with watching the video of the patient talking about their health concerns, the students are provided with a two-page handout that includes: 1) past medical, surgical, vision and dental history; 2) a medication list and lab results; and 3) a social history. Table 3 provides some examples of the standardized patient's health concerns.

\section{Table 3. Clinical Case Details of Geriatric Standardized Patient from IPT Training}

\begin{tabular}{ll}
\hline $\begin{array}{l}\text { Component of the } \\
\text { patient's story }\end{array}$ & \multicolumn{1}{c}{ Examples } \\
\hline Patient complaints & "I have a gum boil that keeps draining" \\
Past medical history & $\begin{array}{l}\text { Congestive heart failure, diabetes, glaucoma, bilateral hip replacements } \\
\text { Sulfa causes anaphylaxis }\end{array}$ \\
\hline Allergies & $\begin{array}{l}\text { Insulin Aspart, furosemide } \\
\text { Medications }\end{array}$ \\
Social history & $\begin{array}{l}\text { children, retired steel mill worker, on a fixed income from Social } \\
\text { Security, has Medicare Parts A and B }\end{array}$ \\
Mobility \& Function & $\begin{array}{l}\text { Uses a cane, four falls in the past year } \\
\text { S/P cataract surgery, last saw eye doctor three years ago }\end{array}$ \\
\hline Vision & Last saw a dentist four years ago \\
\hline Dental &
\end{tabular}




\section{Participants and Setting}

The Office of Interprofessional Curriculum at the University of Alabama at Birmingham hosted three IPT Trainings over three semesters during 2018 and 2019. During the Spring 2018, Fall 2018, and Spring 2019 semesters, a total of 1,015) from nine professional health care programs at UAB and Samford University were invited and participated in the IPT Training. These disciplines included dentistry, medicine, nursing, nutrition, optometry, occupational therapy, pharmacy, physical therapy, and social work. A total of 287 participants completed both the pre- and post-event surveys for a response rate of $28 \%$. There were 77 social work participants and all of these students completed the pre-event survey, and only 20 students completed both the pre- and post-event surveys for a response rate of $26 \%$. For this activity, small group rooms were used to comfortably accommodate groups ranging from 12 to 25 learners. The size of the small groups varies depending on the number of available preceptors and the number of students from each profession. Rooms were equipped with the necessary audio/visual systems.

\section{Design}

The IRB at the University of Alabama at Birmingham granted exemption for the study, "Effect of an Interprofessional Team Training Exercise on Attitudes towards Interprofessional Teams among Students in Health Professions" (IRB_300000478). A preand post-event survey design was used to collect data from the participants. A paper version of the survey was distributed to all participants at the beginning of the IPT Training, and they were asked to complete the survey before the event started. Post-event surveys were collected using Qualtrics, a digital survey tool, and were sent electronically to all participants via email approximately one week after the experience. Pre- and post-event responses were collected from 287 participants.

\section{Measurements}

Demographics and health profession major were collected from each participant. Quantitative measures were used to assess changes in student attitudes towards interprofessional teamwork. The revised version of Dow's IPEC Competency SelfAssessment Tool was used to assess overall attitudes toward interprofessional teamwork (Dow et al., 2014; Lockeman et al, 2019). The original version of this assessment tool consisted of a 42-item self-assessment questionnaire. The Dow Team revised the tool in 2015 and revalidated this version 3 in 2016. It now consists of 16 items assessed on a 5point Likert scale. The tool that was used consists of two domains, one to assess attitudes toward interprofessional interaction and one to assess interprofessional values. Additionally, three items were included to assess the participants overall satisfaction with the learning experience. The items were as follows: a) "This was a valuable learning experience;" b) "The preceptor was well prepared;" and c) "The preceptor effectively led the activity." These items were rated on a 5-point Likert-type scale (1= strongly disagree to $5=$ strongly agree). The participants were also given the opportunity to provide comments at the end of the survey using an open-ended prompt. 


\section{Analyses}

Analyses were conducted using IBM SPSS Statistical Software (Version No. 25). The authors conducted univariate analyses to generate means, frequencies and proportions for the demographic and outcome variables. Because the data could not be matched by participant between pre- and post-event, to look at differences between the social work students' pre- and post-event scores, cross tabulations and T-tests for unequal variances were conducted. The analyses used an alpha level of .05 for all statistical tests. Because of the low number of qualitative comments, no thematic analysis could be completed, but representative comments are provided in the results section for context.

\section{Results}

While students from multiple professions participated in this event, we were interested in how the social work students' attitudes toward interprofessional teamwork changed due to this training. Table 4 provides demographic information of all the student participants who completed both the pre- and post-event survey, specifically, in terms of race, gender and major. Most of the participants identified as female (69\%), white (54\%), and between the ages of 20-29 years (93\%). Additionally, Table 4 shows the demographic information for all social work students who completed both the pre- and post-event survey and the just the pre-event survey.

Table 4. Demographics of Students completing IPT Training, 2018-2019

\begin{tabular}{|c|c|c|c|c|}
\hline \multirow[b]{3}{*}{ Demographics } & \multirow[b]{3}{*}{$\begin{array}{c}\text { All } \\
(n=287)\end{array}$} & \multicolumn{3}{|c|}{$\mathrm{n}(\%)$} \\
\hline & & \multicolumn{2}{|c|}{ Pre \& Post } & \multirow{2}{*}{$\begin{array}{c}\text { Pre- Only } \\
\text { SWK}^{*} \\
(\mathrm{n}=77)\end{array}$} \\
\hline & & $\begin{array}{c}\text { Non-SWK } \\
(n=267)\end{array}$ & $\begin{array}{c}\text { SWK* }^{*} \\
(\mathrm{n}=20)\end{array}$ & \\
\hline \multicolumn{5}{|l|}{ Gender } \\
\hline Female & $199(69 \%)$ & $180(67 \%)$ & $19(95 \%)$ & $65(84 \%)$ \\
\hline Male & $86(30 \%)$ & $85(32 \%)$ & $1(5 \%)$ & $10(13 \%)$ \\
\hline Missing & $2(<1 \%)$ & $2(<1 \%)$ & & $2(3 \%)$ \\
\hline \multicolumn{5}{|l|}{ Age (years) } \\
\hline $20-29$ & $268(93 \%)$ & $256(96 \%)$ & $12(60 \%)$ & $54(70 \%)$ \\
\hline $30-39$ & $8(3 \%)$ & $7(3 \%)$ & $1(5 \%)$ & $9(12 \%)$ \\
\hline $40-49$ & $7(2 \%)$ & $2(<1 \%)$ & $5(25 \%)$ & $7(9 \%)$ \\
\hline $50-59$ & $2(<1 \%)$ & & $2(10 \%)$ & $4(5 \%)$ \\
\hline Missing & $2(<1 \%)$ & & & $3(4 \%)$ \\
\hline \multicolumn{5}{|l|}{ Race } \\
\hline Black & $16(6 \%)$ & $7(3 \%)$ & $9(45 \%)$ & $31(40 \%)$ \\
\hline White & $156(54 \%)$ & $150(56 \%)$ & $6(30 \%)$ & $42(55 \%)$ \\
\hline Hispanic & & & $1(5 \%)$ & $2(3 \%)$ \\
\hline Asian & $15(5 \%)$ & $15(6 \%)$ & & \\
\hline Native American & $6(2 \%)$ & $2(<1 \%)$ & $4(20 \%)$ & $1(1 \%)$ \\
\hline Other & $4(1 \%)$ & $4(1 \%)$ & & \\
\hline Missing & $90(31 \%)$ & $90(33 \%)$ & & $1(1 \%)$ \\
\hline SWK=Social Wor & & & & \\
\hline
\end{tabular}


Among all students participating in the IPT Training, a majority (78\%) rated it a valuable learning experience. In Figure 1, 65\% of social work students "strongly agreed" whereas only $32 \%$ of total participants "strongly agreed" the training was a valuable learning experience. One caveat is that the social work student data is included in the total participant data, thereby positively influencing the response pattern of the group. When social work students were excluded from all participants, only $30 \%$ of all participants found the event to be a valuable learning experience.

Figure 1. Reported Ratings of That IPT Training Provided a Valuable Learning Experience

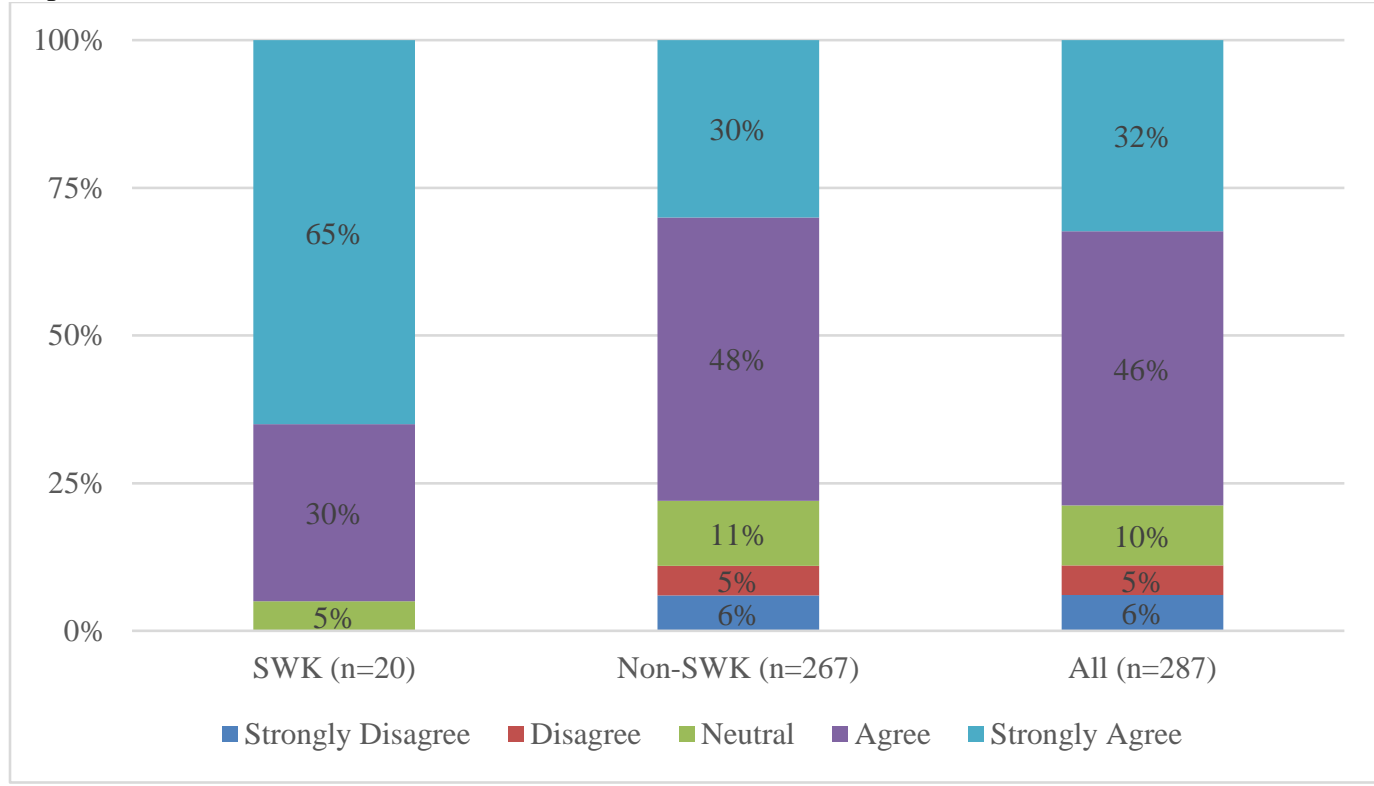

In terms of specific learning outcomes, Table 5 shows the mean scores and standard deviations for pre- and post-event measures for the social work students for the interprofessional competency scale and each of the domains assessed within the tool. These means were compared using independent- sample $t$ tests (alpha value of 0.05 ), and results found no differences between students' attitudes on interprofessional teamwork for the full scale as well as the two domains, interprofessional interaction and interprofessional values.

Table 5. Effects of IPTT Training on Social Work Students' Attitudes About Interprofessional Teamwork

\begin{tabular}{l|c|c|c|c}
\hline & \multicolumn{2}{|c|}{$M(S D)$} & \\
\cline { 2 - 3 } Scales & $\begin{array}{c}\text { Before IPTT } \\
(\mathrm{n}=77)\end{array}$ & $\begin{array}{c}\text { After IPTT } \\
(\mathrm{n}=20)\end{array}$ & $t(d f)$ & Sig. \\
\hline Full Scale & $4.5(0.38)$ & $4.5(0.42)$ & $.095(95)$ & 0.924 \\
Interprofessional Interaction & $4.4(0.48)$ & $4.4(0.50)$ & $-0.378(95)$ & 0.700 \\
Interprofessional Values & $4.7(0.35)$ & $4.6(0.39)$ & $0.750(95)$ & 0.455 \\
\hline
\end{tabular}


A small number of all the participants (10\%) provided written comments about their experience with the IPT training, and while the number does not reflect generalizable qualitative results, they do inform future topics for further exploration for similar interprofessional activities. Table 6 shows representative comments from the social work participants, mapped with possible themes for future exploration based on the Interprofessional Education Collaborative's Core Competencies for Interprofessional Collaborative Practice (IPEC, 2016). For example, Quote \#1 from a social work student could represent that the social work student was apprehensive about working with interprofessional teams or that they embrace commonly held stereotypes about other health care professionals. Similarly, Quote \#2, from another social work student, could reflect that the student had difficulty engaging with students from other health professions or perhaps is unclear about the role of social workers in medical settings. While these quotes are not generalizable, they suggest that rich learning can take place during the IPT Training. Additionally, there is a need for more mixed methodology when assessing student learning with interprofessional activities.

\section{Table 6. Sample Student Comments and Corresponding Themes}

\begin{tabular}{|c|c|}
\hline Sample Quotes & $\begin{array}{l}\text { Possible Themes for Future Qualitative Exploration } \\
\text { based on IPEC Competencies (IPEC, 2016) }\end{array}$ \\
\hline $\begin{array}{l}\text { Quote \#1 - Social Work Student } \\
\text { I was worried that other health care } \\
\text { professionals would speak over me } \\
\text { because I am not a traditional field } \\
\text { of health care, but everyone was } \\
\text { very respectful! }\end{array}$ & $\begin{array}{l}\text { Competency \#1 - Values and ethics for interprofessional } \\
\text { practice } \\
\text { - Embrace the cultural diversity and individual } \\
\text { differences that characterize patients, populations } \\
\text { and the health care team (Sub-competency VE3) } \\
\text { - Maintain competence in one's own profession } \\
\text { appropriate to scope of practice (Sub-competency } \\
\text { VE10) }\end{array}$ \\
\hline $\begin{array}{l}\text { Quote \#2 - Social Work Student } \\
\text { I think it would be helpful if the } \\
\text { client did not have as many health } \\
\text { conditions. I felt like his medical } \\
\text { issues were at the center of the } \\
\text { conversation which made it difficult } \\
\text { for the students in more medical } \\
\text { disciplines to focus on other aspects } \\
\text { of the clients life that were also of } \\
\text { concern. }\end{array}$ & $\begin{array}{l}\text { Competency \#4 - Team and Teamwork } \\
\text { - Engage health and other professionals in shared } \\
\text { patient-centered and population-focused problem- } \\
\text { solving (Sub-competency TT3) } \\
\text { - Reflect on individual and team performance for } \\
\text { individual, as well as team, performance improvement } \\
\text { (Sub-competency TT8) } \\
\text { - Perform effectively on teams in different team roles in } \\
\text { a variety of settings (Sub-competency TT11) }\end{array}$ \\
\hline
\end{tabular}

\section{Discussion}

The present study advances the field of interprofessional education in two ways. First, this innovative program, using a video-based standardized patient, offers a viable interprofessional education experience for health care professions, including social work students, which could be replicated by other institutions. Second, it contributes to our understanding of how an assessment on the effectiveness of team-based interprofessional trainings need to be structured, especially to assess social work students' professional awareness about interprofessional teamwork. 
While social work students did not demonstrate an improvement in attitudes towards interprofessional teamwork, we suspect this was due to the very positive attitudes students reported on our survey instrument before they began the training, possibly due to confidence in their knowledge and skills or wanting to provide socially desirable responses. Additionally, this lack of significant change in attitudes toward interprofessionalism between may be because of the low sample size for social work students. Future assessment of the effectiveness of the program will account for these limitations.

But written comments suggest that this experience may influence students' understanding of specific IPEC competencies and sub-competencies, and this worthy of further investigation. Combined, these data suggest that current scales to assess attitudes toward interprofessional teamwork may be too blunt to assess the complexity of interprofessional competencies across multiple professions. To further assess, in Fall 2019, the team is testing a different instrument, the Interprofessional Collaborative Competency Attainment Survey (Archibald et al., 2014), which uses a post-pre and post-activity methodology. Additionally, post-retrospective research designs may better compensate for the natural tendency of learners to rate themselves higher on attitudes and knowledge related to interprofessional competencies prior to an interprofessional learning activity. Future research studies should address these limitations.

Another interesting finding is the marked difference in the reported value of the IPT Training as a learning experience between social work students and all other health professional students, with a higher percentage of social work students reporting the IPT Training as a valuable learning experience. While this is an area for future exploration, one possible explanation for these differences is that social work students at UAB participate in fewer IPE events than the other health care students due to curricula differences and location of the program within the university's administrative structure. Social work students' higher satisfactions scores may be because IPE events are more novel for them. Adding questions about students' prior experience with IPE combined with an open-ended survey question could uncover reasons for this difference in satisfaction with the Training.

\section{Lessons Learned}

This study offers many lessons learned for social work and other health care educators interested in designing and implementing IPE activities. First, the use of a standardized patient model offers several advantages, such as: allowing for a more consistent and inclusive educational experience for this diverse group of learners; and providing a more condensed and efficient version of the training. Second, the transition to the video interview was a welcome change from the point of view of the standardized patient, who appreciated the improvement in role clarity. The individual in the role of the standardized patient reported it was challenging to prepare for the live interviews because of the diversity of clinical information they had to memorize, as well as the potential that they would be asked questions for which they were unprepared. Third, instruments designed to assess attitudes toward interprofessional teamwork are often not adequate to detect a change in attitudes or understanding. Research shows that students often overrate their abilities, thus, when using some pretest instruments they will rate themselves at the high end of the scale leaving little or no room for an increase to be measured post activity (National Association of Colleges 
and Employers [NACE], 2018). More collection of qualitative data may be needed to better understand the social work student experience in a large interprofessional training program. Finally, one potential area for further research is to assess if differences among the small group faculty preceptors have any effect on student learning outcomes. These individuals will have varying levels of comfort facilitating discussion of all aspects of the case and engaging learners from all different healthcare professions. Overall, interprofessional educational activities such as the IPT Training offer social work educators a rich opportunity to improve competencies among social work and other health care students related to teamwork and the contributions of the social work profession to the health care team.

\section{References}

Archibald, P., Muhammad, O., \& Estreet, A. (2016). Business in social work education: A historically Black university's social work entrepreneurship project. Journal of Social Work Education, 52(1), 79-94. https://doi.org/10.1080/10437797.2016.1112643

Badger, L. W., \& MacNeil, G. (2002). Standardized clients in the classroom: A novel instructional technique for social work educators. Research on Social Work Practice, 12(3), 364-374. https://doi.org/10.1177/1049731502012003002

Bays, A. M., Engelberg, R. A., Back, A. L., Ford, D. W., Downey, L., Shannon, S. E., Doorenbos, A. Z., Edlund, B., Christianson, P., Arnold, R. W., O'Connor, K., Kross, E. K., Reinke, L. F., Feemster, L. C., Fryer-Edwards, K., Alexander, S. C., Tulsky, J. A., \& Curtis, J. R. (2014). Interprofessional communication skills training for serious illness: Evaluation of a small-group, simulated patient intervention. Journal of Palliative Medicine, 17(2), 159-166. https://doi.org/10.1089/jpm.2013.0318

Berwick, D. M., \& Hackbarth, A. D. (2012). Eliminating waste in US health care. JAMA, 307(14), 1513-1516. https://doi.org/10.1001/jama.2012.362

Blewett, L. A., Johnson, K., McCarthy, T., Lackner, T., \& Brandt, B. (2010). Improving geriatric transitional care through inter-professional care teams. Journal of Evaluation in Clinical Practice, 16(1), 57-63. https://doi.org/10.1111/j.13652753.2008.01114.x

Bodenheimer, T., \& Sinsky, C. (2014). From triple to quadruple aim: care of the patient requires care of the provider. Annals of Family Medicine, 12(6), 573-576. https://doi.org/10.1370/afm.1713

Council on Social Work Education. (2015). 2015 Educational Policy and Accreditation Standards for baccalaureate and master's social work programs. Alexandria, VA: Author. https://www.cswe.org/getattachment/Accreditation/AccreditationProcess/2015-EPAS/2015EPAS Web FINAL.pdf.aspx

Dana, M. B., \& Sheps, C. G. (1968). Trends and Issues in Interprofessional Education. Journal of Education for Social Work, 4(2), 35-41. https://doi.org/10.1080/00220612.1968.10778686

Dow, A. W., DiazGranados, D., Mazmanian, P. E., \& Retchin, S. M. (2014). An exploratory study of an assessment tool derived from the competencies of the 
interprofessional education collaborative. Journal of Interprofessional Care, 28(4), 299-304. https://doi.org/10.3109/13561820.2014.891573

Forgey, M. A., Badger, L., Gilbert, T., \& Hansen, J. (2013). Using Standardized Clients to Train Social Workers in Intimate Partner Violence Assessment. Journal of Social Work Education, 49(2), 292-306. https://doi.org/10.1080/10437797.2013.768482

Foronda, C., MacWilliams, B., \& McArthur, E. (2016). Interprofessional communication in healthcare: An integrative review. Nurse Education in Practice, 19, 36-40. https://doi.org/10.1016/j.nepr.2016.04.005

Freeth, D., \& Reeves, S. (2004). Learning to work together: Using the presage, process, product (3P) model to highlight decisions and possibilities. Journal of Interprofessional Care, 18(1), 43-56. https://doi.org/10.1080/13561820310001608221

Health Professions Accreditors Collaborative. (2019). Guidance on developing quality interprofessional education for the health professions. Health Professions Accreditors Collaborative. https://healthprofessionsaccreditors.org/wpcontent/uploads/2019/02/HPACGuidance02-01-19.pdf

Hitchcock, L. I., King, D. M., Johnson, K., Cohen, H., \& Mcpherson, T. L. (2019). Learning outcomes for adolescent SBIRT simulation training in social work and nursing education. Journal of Social Work Practice in the Addictions, 19(1-2), 47-56. https://doi.org/10.1080/1533256X.2019.1591781

Hitchcock, L. I., Peterson, D. T., Debiasi, L., Shipman, S., Varley, A., \& White, M. L. (2018). Learning about poverty through simulation: A pilot evaluation. Journal of Social Work Education, 54(3), 517-531. https://doi.org/10.1080/10437797.2018.1434427

Homeyer, S., Hoffmann, W., Hingst, P., Oppermann, R. F., \& Dreier-Wolfgramm, A. (2018). Effects of interprofessional education for medical and nursing students: Enablers, barriers and expectations for optimizing future interprofessional collaboration - a qualitative study. BMC Nursing, 17(1), 1-10. https://doi.org/10.1186/s12912-018-0279-x

Interprofessional Education Collaborative [IPEC]. (2016). Core competencies for interprofessional collaborative practice: 2016 update. Author. https://hsc.unm.edu/ipe/resources/ipec-2016-core-competencies.pdf

IPEC. (2019). Home page. Retrieved October 2, 2019, from IPEC Interprofessional Education Collaborative website, http://ipecollaborative.org/news--announcements.html

Jones, B., \& Phillips, F. (2016). Social work and interprofessional education in health care: A call for continued leadership. Journal of Social Work Education, 52(1), 1829. https://doi.org/10.1080/10437797.2016.1112629

Kaminetzky, C. P., Beste, L. A., Poppe, A. P., Doan, D. B., Mun, H. K., Woods, N. F., \& Wipf, J. E. (2017). Implementation of a novel population panel management 
curriculum among interprofessional health care trainees. BMC Medical Education, 17(1), 1-8. https://doi.org/10.1186/s12909-017-1093-y

Kaplonyi, J., Bowles, K.-A., Nestel, D., Kiegaldie, D., Maloney, S., Haines, T., \& Williams, C. (2017). Understanding the impact of simulated patients on health care learners' communication skills: A systematic review. Medical Education, 51(12), 1209-1219. https://doi.org/10.1111/medu.13387

Lempicki, K. A., \& Holland, C. S. (2018). Web-based versus face-to-face interprofessional team encounters with standardized patients. Currents in Pharmacy Teaching and Learning, 10(3), 344-351. https://doi.org/10.1016/j.cpt1.2017.11.014

Lockeman, K. S., Dow, A. W., \& Randell, A. L. (2019). Validity evidence and use of the IPEC Competency Self-Assessment, Version 3. Journal of Interprofessional Care, 17. https://doi.org/10.1080/13561820.2019.1699037

Logie, C. H., Bogo, M., \& Katz, E. (2015). "I didn’t feel equipped": social work students' reflections on a simulated client "coming out." Journal of Social Work Education, 51(2), 315-328. https://doi.org/10.1080/10437797.2015.1012946

Lopez, S. A., Torres, A., \& Norwood, P. (1998). Building partnerships: A successful collaborative experience between social work and education. Children \& Schools, 20(3), 165-176. https://doi.org/10.1093/cs/20.3.165

Mooradian, J. K. (2008). Using simulated sessions to enhance clinical social work education. Journal of Social Work Education, 44(3), 21-36. https://doi.org/10.5175/JSWE.2008.200700026

National Association of Colleges and Employers [NACE]. (2018, February 19). Are college graduates "career ready"? Retrieved October 11, 2019, from https://www.naceweb.org/career-readiness/competencies/are-college-graduatescareer-ready/

Palaganas, J. C., Maxworthy, J. C., Epps, C. A., \& Mancini, M. E. (2014). Defining excellence in simulation programs. Lippincott Williams \& Wilkins.

Reis, P. J., Faser, K., \& Davis, M. (2015). A framework for web-based interprofessional education for midwifery and medical students. Journal of Midwifery \& Women's Health, 60(6), 713-717. https://doi.org/10.1111/jmwh.12331

Rothrock, A., Sawyer, P., Ford, C., Ritchie, C., \& Brown, C. (2013). Developing Comprehensive Care Plans for Older Adults interprofessional team training session: Teaching interprofessional health profession students the importance of working in teams. MedEdPORTAL Publications, 9, 9527. https://doi.org/10.15766/mep_2374$\underline{8265.9527}$

Rubin, M., Konrad, S. C., Nimmagadda, J., Scheyett, A., \& Dunn, K. (2018). Social work and interprofessional education: Integration, intersectionality, and institutional leadership. Social Work Education, 37(1), 17-33. https://doi.org/10.1080/02615479.2017.1363174 
Schlegel, C., Woermann, U., Shaha, M., Rethans, J. J., \& van der Vleuten, C. (2012). Effects of communication training on real practice performance: A role-play module versus a standardized patient module. Journal of Nursing Education, 51(1), 16-22. https://doi.org/10.3928/01484834-20111116-02

Vandsburger, E., Duncan-Daston, R., Akerson, E., \& Dillon, T. (2010). The effects of poverty simulation, an experiential learning modality, on students' understanding of life in poverty. Journal of Teaching in Social Work, 30(3), 300-316. https://doi.org/10.1080/08841233.2010.497129

Wamsley, M., Staves, J., Kroon, L., Topp, K., Hossaini, M., Newlin, B., Lindsay, C., \& O'Brien, B. (2012). The impact of an interprofessional standardized patient exercise on attitudes toward working in interprofessional teams. Journal of Interprofessional Care, 26(1), 28-35. https://doi.org/10.3109/13561820.2011.628425

Washburn, M., \& Zhou, S. (2018). Teaching note-Technology-enhanced clinical simulations: Tools for practicing clinical skills in online social work programs. Journal of Social Work Education, 54(3), 554-560. https://doi.org/10.1080/10437797.2017.1404519

Wharton, T., \& Burg, M. A. (2017). A mixed-methods evaluation of social work learning outcomes in interprofessional training with medicine and pharmacy students. Journal of Social Work Education, 53(sup1), S87-S96. https://doi.org/10.1080/10437797.2017.1288592

White, M. J., Gutierrez, A., McLaughlin, C., Eziakonwa, C., Newman, L. S., White, M., Thayer, B., Davis, K., Williams, M., \& Asselin, G. (2013). A pilot for understanding interdisciplinary teams in rehabilitation practice. Rehabilitation Nursing 38(3), 142152. https://doi.org/10.1002/rnj.75

World Health Organization. (2010). Framework for action on interprofessional education and collaborative practice. Author. https://apps.who.int/iris/bitstream/handle/10665/70185/WHO_HRH_HPN_10.3_eng. pdf;jsessionid=17E9AF821CCECC269A55481EB89E8A27? sequence=1

Wu, F. M., Rubenstein, L. V., \& Yoon, J. (2018). Team functioning as a predictor of patient outcomes in early medical home implementation. Health Care Management Review, 43(3), 238-248. https://doi.org/10.1097/HMR.0000000000000196

Author note: Address correspondence to Laurel Iverson Hitchcock, Department of Social Work, University of Alabama at Birmingham, UH 3148, $17202^{\text {nd }}$ Ave South, Birmingham, AL 35294. Email: lihitch@uab.edu

Acknowledgements: We gratefully acknowledge Drs. Christine Ritchie, Cynthia J. Brown, and Angela Rothrock who developed and implemented the original version of the program supported by in part by funds from the Bureau of Health Professions, Health Resources and Services Administration, Department of Health and Human Services. We also owe gratitude to Danny Andrews, our standardized patient who participated in all live and video versions of the program. 